\title{
Lead Oxide-Graphite Composite Electrode for pH Measurement
}

\author{
Ranjan Nepal and Raja Ram Pradhananga \\ Central Department of Chemistry \\ Tribhuvan University, Kathmandu Nepal \\ e-mail: pradhananga.rajaram@yahoo.com
}

\begin{abstract}
Lead oxide-graphite composite electrode for $\mathrm{pH}$ measurement had been fabricated with different percentage of $\mathrm{PbO}_{2}$ in the composite. The proportions of lead oxide affected the sensitivity of the electrode. The electrode composed of 50\% lead oxide and 50\% graphite gave reproducible result and behaved in Nernstian manner with a potential gradient of $-58.8 \pm 0.3 \mathrm{mV}$ per unit change in $\mathrm{pH}$. Metal ions such as iron (II), iron (III) and lead (II) interfered in the measurement of $\mathrm{pH}$, while silver (I), copper (II), oxidizing agents such as dichromate and permanganate do not interfere. In absence of interfering ion, the lead oxide-graphite composite electrode could be used for the measurement of $\mathrm{pH}$ from 2 to 11 . This electrode can also be used as an indicator electrode for acid base titrations. Low cost, quick response, easy to fabricate are some of the advantages of the lead oxide-graphite composite electrode. This electrode is also found to be sensitive to $\mathrm{Pb}^{2+}$-ions and can be used as a $\mathrm{Pb}^{2+}$-ion sensor up to $10^{-4} \mathrm{M}$.
\end{abstract}

Key words: composite electrode, glass electrode, interfering ions, potentiometric titrations, surface modification

\section{Introduction}

The determination $\mathrm{pH}$ of a solution is very important in many of chemistry, biochemistry, microbiology work and is one of the most important tasks in analytical laboratory. Among the various methods, the use of glass electrodes has been widely adopted for $\mathrm{pH}$ measurement due to its good sensitivity, selectivity, and stability (Galster 1991). However, glass electrodes have several disadvantages related to the intrinsic nature of the glass membrane - high impedance of the membrane, difficulty of miniaturization, mechanical fragility and chemical instability in corrosive systems. Moreover, it presents deviations of the Nernstian behavior for very high and low $\mathrm{pH}$ values (Lemos et al. 2008). Consequently, non-glass based hydrogen ion-selective electrodes are continuously investigated and such electrodes are preferred over glass electrodes owing to robustness of such electrodes.

Carbon electrodes had been used in many electrochemical works but its use as $\mathrm{pH}$ sensors is not very much attractive owing to the low reproducibility, narrow measurable $\mathrm{pH}$ range and instability of standard potential. However, the response of the electrode with concentration changes of hydrogen ions can be improved by oxidation of the carbon surface by suitable oxidant whereby quinhydrone-like surface oxides are formed and thereby improve the sensitivity of the electrode to the activity of hydrogen ion (Migdley et al. 1983). The change in electrode potential per unit change in $\mathrm{pH}$ also depends on extent of surface oxidation and nature and composition of the oxidant used for oxidation of carbon surface. Such carbon electrodes were also found to be applicable as indicator electrodes in acidbase titrations with greater potential jumps at end point compared to glass electrodes (Kahlert 2008). Another approach of producing $\mathrm{pH}$ sensitive carbon based electrodes is to use composite electrodes by incorporating some hydrogen sensitive material in carbon. Szepesváry and Pungor (1971) reported the use of silicone rubber based graphite electrode as 
indicator electrodes in acid-base titrations. Teixeira $e t$ al. $(1999,2000,2001,2002)$ proposed various carbonepoxy composite electrodes modified with silica gel or different metal oxides such as $\mathrm{PbO}_{2}, \mathrm{MnO}_{2}$ or $\mathrm{Fe}_{2} \mathrm{O}_{3}$. All these electrodes behave in sub-Nernstian manner with slope ranging from 40 to $54 \mathrm{mV}$ per unit change in $\mathrm{pH}$.

In the present work, we investigated the possibility of using lead oxide and modified graphite as a low cost tool for $\mathrm{pH}$ measurement. The electrode was constructed from a mixture of $\mathrm{PbO}_{2}$ and graphite power with solid paraffin as a binder. The effect of composition $\left(\mathrm{PbO}_{2}\right.$ and graphite) on the response and the $\mathrm{pH}$ dependence of the potential in aqueous media were investigated. The stability and reproducibility of the electrode in different buffer solutions were studied. The effect of different interfering ion on $\mathrm{pH}$ determination and possibility of using the electrode for the determination of $\mathrm{Pb}^{2+}$ were also investigated.

\section{Methodology}

\section{Surface modification of graphite}

The oxidative surface modification of commercial graphite powder was achieved by reflux boiling of the graphite powder with $1: 1$ nitric acid in a weight ratio $1: 10$ for $60 \mathrm{~min}$. The mixture was cooled and filtered; the residue was filtered off and rinsed with water until the rinsing water was no longer acidic. Composite electrode was prepared using this surface oxidized graphite power.

\section{Electrode preparation}

The composite active materials used in these electrodes were prepared by mixing $\mathrm{PbO}_{2}$ (Qualigens fine chemicals), surface oxidized graphite in following mass ratio: 1) 25:75 2) 50:50 3) 75:25 with constant paraffin wax binder. The mixture was heated until the paraffin melted and thoroughly mixed, then the paste was applied over silver disc and mounted in a polypropylene rod of diameter $10 \mathrm{~mm}$. The electric contact was made by the copper wire soldered to silver plate.

\section{Equipment}

All potentiometric measurements were conducted at laboratory temperature with $\mathrm{PbO}_{2}$-graphite composite electrode and an $\mathrm{Ag} / \mathrm{AgCl}, \mathrm{KCl}$ (satd.) reference electrode. The electrochemical cell used for potential measurements was:

$\mathrm{Ag} / \mathrm{AgCl}(\mathrm{s}), \mathrm{KCl}$ (satd.) || test solution| $\mid \mathrm{PbO}_{2}$-graphite composite electrode/Ag

EMF measurement was carried out using Oswa digital potentiometer under constant stirring with a Teflon coated magnetic stirrer

\section{Results and Discussion \\ Effect of electrode composition}

The effect of electrode composition on the response of the lead oxide-graphite composite electrode was evaluated by measuring potential at different $\mathrm{pH}$. The plots of EMF of the cell as a function of $\mathrm{pH}$ for the electrodes of different compositions are shown in Figure 1. The corresponding slope of such plots with correlation coefficient is given in Table 1 . In general, all the electrodes respond linearly with $\mathrm{pH}$, however, slope of such plots are found to depend on the composition of the electrode. The slope increased with increase in percentage of $\mathrm{PbO}_{2}$ up to $50 \%$, after that slope decreased. The slopes given in the Table is the average of three measurements obtained from regression analysis of EMF vs. pH plot. If we look at Table 1 we will find that the sensitivity of the electrode increases with increase in percentage of $\mathrm{PbO}_{2}$ up to $50 \%$, as indicated by increase in slope of the $\mathrm{E}_{\text {cell }} \mathrm{vs} \mathrm{pH}$ plot. The increase in sensitivity of the electrode with increase in $\mathrm{PbO}_{2}$ content may be attributed to the increase in activity of $\mathrm{PbO}_{2}$ in the composite and $50 \% \mathrm{PbO}_{2}$ is the optimum the amount. With increase in $\mathrm{PbO}_{2}$ above $50 \%$, the slope decreases again and this means that the sensitivity of the electrode decreases. This may be due to the decrease in efficiency of the electrode transfer reaction due to increase in resistance of the electrode. With lower percentage of conducting graphite, the conductivity of the electrode decrease thereby occurrence of some other side reaction other than the reaction responsible to hydrogen ion sensitivity may takes place.

The electrode reaction responsible for hydrogen ion sensitivity of the electrode may be represented as follow (Eftekhari 2003):

$\mathrm{PbO}_{2}(\mathrm{~s})+2 \mathrm{H}^{+}(\mathrm{aq})+2 \mathrm{e}^{-} \rightleftharpoons \mathrm{PbO}(\mathrm{s})+\mathrm{H}_{2} \mathrm{O} \ldots \ldots .$. 
And corresponding equation for electrode potential is

$$
\mathrm{E}=\mathrm{E}^{\circ}-\mathrm{S} \mathrm{P}^{\mathrm{H}}
$$

where $\mathrm{E}^{\mathrm{o}}$ is the standard electrode potential and $\mathrm{S}$ is the potential gradient per unit $\mathrm{pH}$ change. For an ideal electrode, the slope should be $59.1 \mathrm{mV}$ at $25^{\circ} \mathrm{C}$. In the present investigation the slope was found to be $58.8 \mathrm{mV}$ for the electrode with $50 \% \mathrm{PbO}_{2}$ and $50 \%$ graphite. This value was the average value of three measurements. The correlation coefficient was found to be 0.999. This means that the $\mathrm{PbO}_{2}$ graphite composite electrode with $50 \% \mathrm{PbO}_{2}$ could be a very good electrode for the $\mathrm{pH}$ measurement.

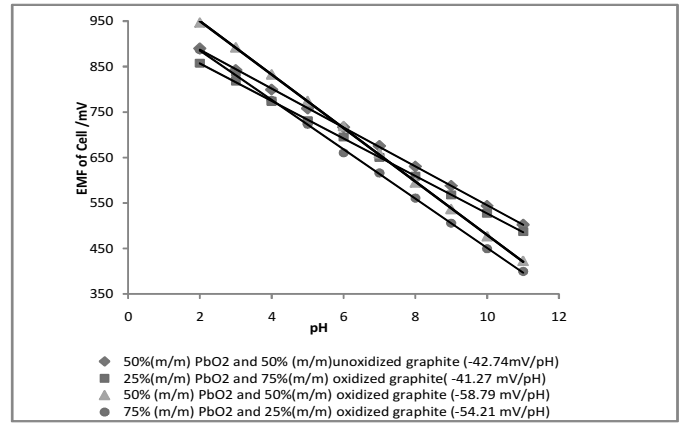

Fig. 1. $\mathrm{P}^{\mathrm{H}}$ dependence of EMF of the cell of lead oxidegraphite composite electrodes with different compositions

Table 1. Response of electrode with $\mathrm{pH}$ with standard deviation and correlation coefficient

\begin{tabular}{l|l|l|l|l}
\hline Electrode & Intercept & Slope & Correlation coefficient & Standard deviation \\
\hline $\mathrm{E}_{25-\mathrm{ox}}$ & 940 & -41.27 & 0.999 & 0.10 \\
$\mathrm{E}_{50}$ & 973 & -42.47 & 0.999 & 0.48 \\
$\mathrm{E}_{50-\mathrm{ox}}$ & 1067 & -58.79 & 0.999 & 0.28 \\
$\mathrm{E}_{75-\mathrm{ox}}$ & 994 & -54.21 & 0.998 & 0.21 \\
\hline
\end{tabular}

$\mathrm{E}_{25 \text {-ox }} 25 \%$ lead oxide $+75 \%$ oxidized graphite

$\mathrm{E}_{50} \quad 50 \%$ lead oxide $+50 \%$ unoxidized graphite

$\mathrm{E}_{50 \text {-ox }} \quad 50 \%$ lead oxide $+50 \%$ oxidized graphite

$\mathrm{E}_{75-\mathrm{ox}} \quad 75 \%$ lead oxide $+25 \%$ oxidized graphite

\section{Response of lead ion}

The electrode is found to be sensitive to the concentration of lead ion. The electrode reaction responsible for $\mathrm{Pb}^{2+}$ ion sensitivity may be portrayed as follow (Lima et al. 2005):

$\mathrm{PbO}_{2}(\mathrm{~s})+4 \mathrm{H}^{+}(\mathrm{aq})+2 \mathrm{e}^{-} \rightleftharpoons \mathrm{Pb}^{2+}(\mathrm{aq})+2 \mathrm{H}_{2} \mathrm{O}$ (1)

At constant $\mathrm{pH}$, the electrode potential of the electrode may be written as,

$\mathrm{E}=\mathrm{E}^{\circ}-\frac{\varepsilon}{2} \hat{\mathrm{a}} \log \left[\mathrm{Pb}^{2+}\right]$

\section{Here $\beta$ is the efficiency of electrode}

The plot of EMF of the cell against $-\log \left[\mathrm{Pb}^{2+}\right]$ at $\mathrm{pH}$ 5 is shown in Fig. 2. The plot is linear one with slope equal to $-57.67 \pm 0.49 \mathrm{mV}$. This clearly means that the composite electrode can be used as a lead selective electrode in the concentration range of $\mathrm{Pb}^{2+}$ from 10 ${ }^{1}$ to $10^{-4} \mathrm{M}$ The observed experimental data of the present investigation may be fitted to the above equation with the value of efficiency $\beta$ equal to 1.95 .

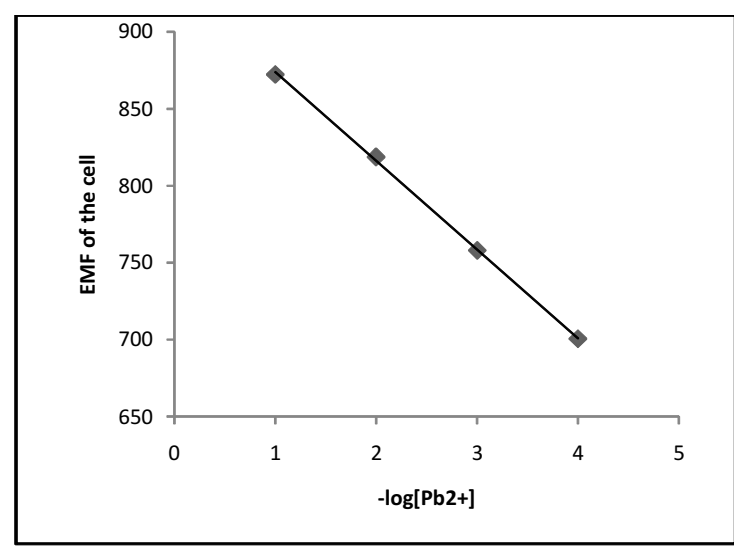

Fig. 2. Effect of lead ion concentration at constant $\mathrm{P}^{\mathrm{H}} 5$

This electrode was thus found to be sensitive to $\mathrm{Pb}^{2+}$ ions and could be used as a $\mathrm{Pb}^{2+}$ ion sensor up to $10^{-}$ ${ }^{4} \mathrm{M}$ concentration of lead ion at $\mathrm{pH} 5$.

\section{Potentiometric titrations}

Potentiometric titration of acids and bases in aqueous media were performed by using composite electrode with $50 \% \mathrm{PbO}_{2}$ as an indicator electrode. The electrode attained equilibrium potential within $15 \mathrm{~s}$. Fig. 3 presents a typical potentiometric titration curves for the titration of $10 \mathrm{ml} 0.1 \mathrm{M}$ acetic acid and $0.1 \mathrm{M}$ hydrochloric acid with a $0.1 \mathrm{M}$ sodium hydroxide. In both cases clear inflexion were observed and the results were in 
agreement with the theoretically expected value. So, it can be concluded that lead oxide graphite composite electrode can serve as a low cost indicator electrodes for $\mathrm{pH}$-metric titration. Similarly, titration of phosphoric acid with sodium hydroxide was performed. A typical titration curve is shown in Figure 4. As expected, a clear first and second inflection points were observed. Titration of a mixture of strong acid and a weak acid and titration of sodium carbonate with hydrochloric acid were also performed using lead oxide graphite composite electrode. A typical potentiometric titration curve for the titration of sodium carbonate with hydrochloric acid is shown in Fig. 5.

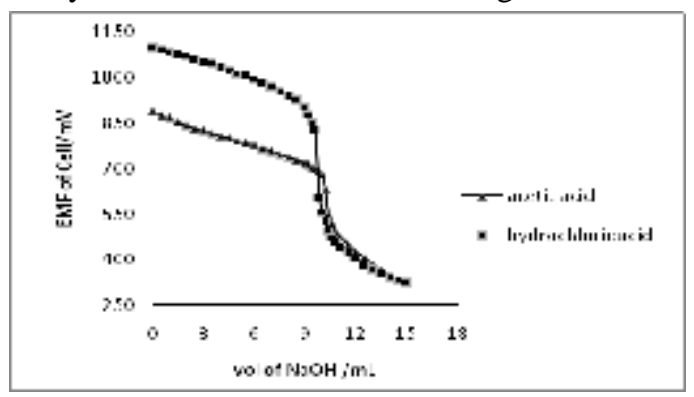

Fig. 3. Potentiometric titration curve for the titration of $10 \mathrm{ml} 0.1 \mathrm{Ml}$ acetic acid and $0.1 \mathrm{M}$ hydrochloric acid solutions separately with $0.1 \mathrm{M}$ sodium hydroxide solution.

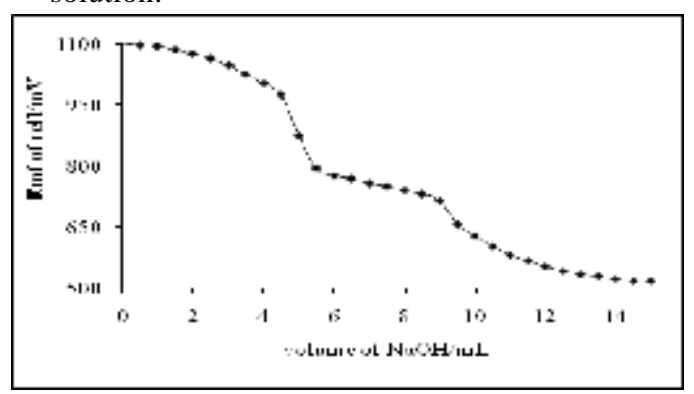

Fig. 4. Potentiometric titration curve of $0.1 \mathrm{M}$ phosphoric acid with $0.1 \mathrm{~N}$ sodium hydroxide

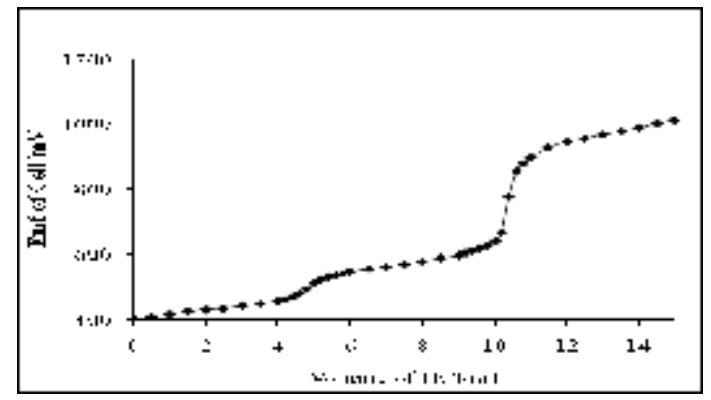

Fig. 5. Potentiometric titration curve of 0.1 Nsodium carbonate with $0.1 \mathrm{~N}$ hydrochloric acid

\section{Effect of interference ions}

The interference due to different oxidizing agent and metallic salts on the measurement of $\mathrm{pH}$ using lead oxide graphite composite electrode was studied. For this oxidizing agent/salt solution was added to the buffer solution till the concentration of interfering ions increased from $5 \times 10^{-3} \mathrm{M}$ to $210^{-2} \mathrm{M}$ and the change in $\mathrm{p}^{\mathrm{H}}$ was determined. There was hardly any change in $\mathrm{pH}$ with the addition of $\mathrm{KMnO}_{4}, \mathrm{~K}_{2} \mathrm{Cr}_{2} \mathrm{O}_{7} \mathrm{AgNO}_{3}$, and $\mathrm{CuSO}_{4}$ but there was a change in $\mathrm{P}^{\mathrm{H}}$ with the addition of $\mathrm{FeSO}_{4}, \mathrm{~Pb}\left(\mathrm{NO}_{3}\right)_{2}$ and $\mathrm{FeCl}_{3}$.this is graphically shown in Fig. 6.

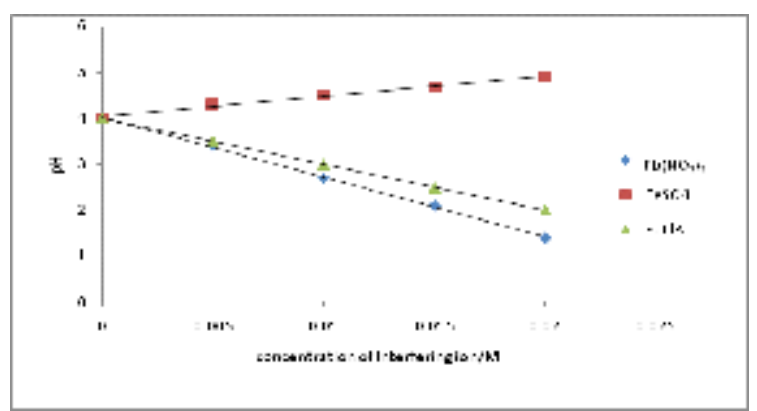

Fig. 6. Change in $\mathrm{pH}$ of solution with addition of interfering ion

Since the electrode is also sensitive to lead ion, it is expected that the addition of lead ion in solution interfere in the determination of $\mathrm{pH}$.

A sensitivity $\mathrm{pH}$ sensor can be easily constructed in the laboratory from lead oxide graphite composite mixture containing equal weight of lead oxide and graphite with paraffin wax as binder. The electrode behaves in Nernstian manner with a potential gradient of $58.8 \pm 0.3 \mathrm{mV}$ per unit change in $\mathrm{pH}$ at $25^{\circ} \mathrm{C}$ and can be used in $\mathrm{pH}$ range from 2 to 11 . The electrode can be used as indicator electrode for potentiometric titration of acid with base and vice versa. $\mathrm{Fe}^{2+}, \mathrm{Fe}^{3+}$ and $\mathrm{Pb}^{2+}$ ions interfere while oxidizing agents such as permanganate and dichromate do not interfere in the determination of $\mathrm{pH}$. The electrode also responses to $\mathrm{Pb}^{2+}$ ion in the concentration range from $10^{-1}$ to $10^{-4} \mathrm{M}$. The electrode is simple to use, robust in nature, readily constructed and inexpensive. The electrode can be used for $\mathrm{p}^{\mathrm{H}}$ measurement in teaching and other institute where high precision is not required.

\section{Acknowledgements}

The first author received financial support from University Grant Commission, Nepal for M.Sc. 


\section{Ranjan Nepal \& Raja Ram Pradhananga/Lead oxide-graphite composite.....}

dissertation. The authors gratefully acknowledged the Central Department of Chemistry, Tribhuvan University, Kirtipur, Nepal for providing available facilities to conduct this work.

\section{References}

da Silva, G. M., S. G. Lemos, L. A. Pocrifka, P. D. Marreto,

A. V. Rosario and E. C. Pereira. 2008. Development of low-cost metal oxide $\mathrm{pH}$ electrodes based on the polymeric precursor method. Anal. Chim. Acta 16: 36-41.

Eftekhari, A. 2003. pH sensor based on deposited film of lead oxide on aluminum substrate electrode. Sens. Actuators B 88: 234-238.

Galster, H. 1991. pH Measurements - Fundamentals, Methods, Instruments, Applications. VCH Publishers, New York.

Kahlert, H. 2008. Functionalized carbon electrodes for $\mathrm{pH}$ determination J. Solid State Electrochem. 12: 12551266.

Lima, A.C., A.A. Jesus, M.A. Tenan, A.F.S. Silva, A. F. Oliveira. 2005. Evaluation of a high sensitivity $\mathrm{PbO}_{2}$ pH -sensor. Talanta 66: 225-228.
Midgley, D., and D. E. Mulcahy. 1983. Carbon Substrate Ion-Selective Electrodes. Ion Sel. Electrode Rev. 5: 165-241.

Szepesvary, E., and E. Pungor. 1971. Potentiometric determination of acids and bases with a silicone rubberbased graphite electrode as indicating electrode Anal. Chim. Acta. 54: 199-208.

Teixeira, M. F. S., L. A. Ramos, E. A. Neves, and O. FatibelloFilho. 2000. Potentiometric determination of acids and bases using a silica gel based carbon-epoxy indicator electrode. Fresenius J. Anal. Chem. 36: 86-89.

Teixeira, M. F. S., L. A., Ramos, O. Fatibello-Filho, and E. T. G. Cavalheiro. 2001. $\mathrm{PbO}_{2}$-based graphite-epoxy electrode for potentiometric determination of acids and bases in aqueous and aqueous-ethanolic media. Fresenius J.Anal. Chem. 37:383-386.

Teixeira, M. F. S., F. C. Moraes, O. Fatibello-Filho, L. C. Ferracin, R. C. Rocha-Filho, and N. Bocchi.1999. A novel ë- $\mathrm{MnO}_{2}$-based graphite- epoxy electrode for potentiometric determination of acids and bases. Sens. Actuators B 56: 169-174.

Teixeira, M. F. S., L. A. Ramos, E. A. Neves, and E. T. G. Cavalheiro. 2002. A solid $\mathrm{Fe}_{2} \mathrm{O}_{3}$ based carbon-epoxy electrode for potentiometric measurements of $\mathrm{pH}$. Portugaliae Electrochimica Acta 20: 139-149. 
Nepal Journal of Science and Technology Vol. 15, No.1 (2014) 61-66 